\title{
Timely use of Technology to Reduce Perpetuate Stress Impacts
}

\author{
Shubhangi Gond, Bhavna Ambudkar, Afzal Ali Syed
}

\begin{abstract}
Stress has become a common thing in today's life. Because of the fast pace, it is a top health concern. Psychologists say that if they don't learn healthy ways to manage stress now, it could have serious long-term health implications, such as depression, anxiety, high blood pressure, diabetes. Currently people are suffering from stress issues everywhere. Since last few decades stress has been detected in most of the people and there has been recorded severely increasing effect of stress on human body. Stress can alter complete health which leads to reducing the tolerating power of the human. In metro cities this condition is more severe. Hence it is necessary to identify stress before it causes any serious harm and treat on it. In this project we are presenting stress detection technique and lower it with the help of Music therapy. As there are many benefits of music so by taking advantage of it we are minimizing stress level to normal state. Detection of stress using brainwaves is a non-invasive method. We have selected 42 students who were about to go for their exam. Firstly we have recorded brainwaves before they were going to exam, then immediately after finishing their exam we have recorded brainwaves lastly they were allowed to listen to their favorite music and then recorded their brainwaves. From analysis it is clear that stressed brainwave were reduced to $29 \%$ by listening music.
\end{abstract}

Keywords : Brainwaves, stress, music impacts, stress relief.

\section{INTRODUCTION}

From the survey made by Global Health Organization, $80 \%$ of employees are suffering from stress at work, $60 \%$ of employees want to quit their jobs due to workplace stress, 1 in 2 employees suffers from anxiety and depression, $90 \%$ of employees are interested to participate in corporate stress management programs[5]. Fig.1 shows Stress Statistics of India, from which we find that in India maximum stress of $36.8 \%$ is found at work place where people don't get respect as they desire[4]. Secondly because of personal responsibilities, $30.1 \%$ India's people are stressed. Next, due to growing population there is tremendous competition in almost every field. This gives rise to stress of winning which can causes hypertension and in India this stress contribute to

Revised Manuscript Received on December 30, 2019.

* Correspondence Author

Shubhangi Gond*, Electronics and Telecommunication, Dr. D. Y. Patil Institute of Technology Pimpri, Pune, India.

Bhavna Ambudkar, Electronics and Telecommunication, Dr. D. Y. Patil Institute of Technology Pimpri, Pune, India.

Afzal Ali Syed, Electronics and Telecommunication, Dr. D. Y. Patil Institute of Technology Pimpri, Pune, India.

(c) The Authors. Published by Blue Eyes Intelligence Engineering and Sciences Publication (BEIESP). This is an open access article under the CC BY-NC-ND license (http://creativecommons.org/licenses/by-nc-nd/4.0/)
$23.6 \%$ of total stress as shown in figure 1 . Approximately 1 out of 75 people may experience panic disorder. Depression is among the leading causes of disability worldwide. Fewer than $25 \%$ of those with depression world-wide have access to effective treatments [2].

There are some types of stress such as acute stress, episodic acute stress, chronic stress. Acute stress is most often caused by reactive thinking. Negative thoughts predominate about situations or events that have recently occurred, or upcoming situations, events, or demands in the near future[1]. Acute stress causes signs and symptoms in the body + brain + emotions, but does not cause the significant amount of damage as Episodic Stress and Chronic stress.

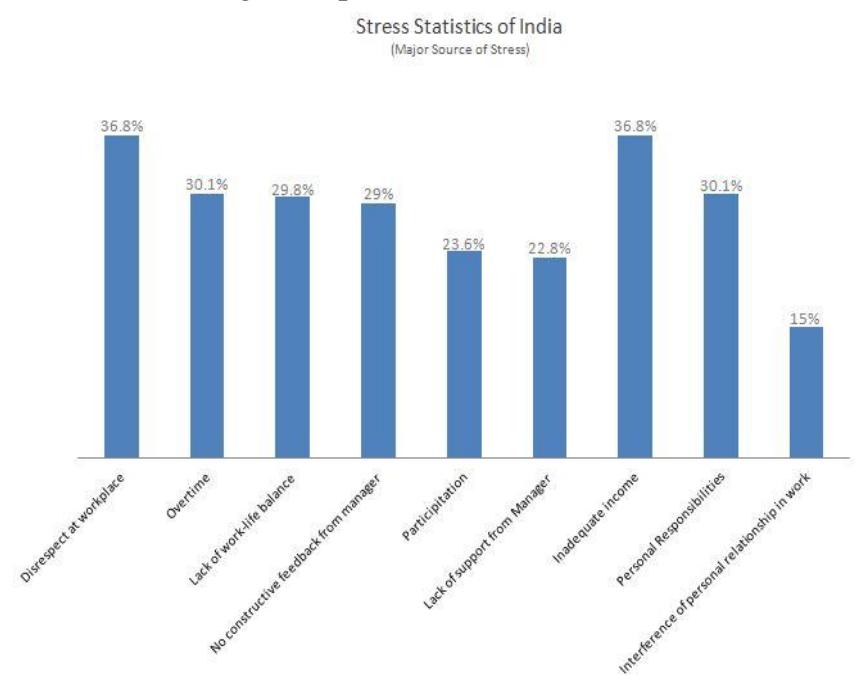

Source: $\underline{\text { SHRM[4] }}$

Fig. 1.Stress statistics of India

The individuals who frequently suffer acute stress often live a life of chaos and crisis. They are always in a rush or feel pressured. They take on many responsibilities, and usually can not stay organized with so many time demands. These individuals are perpetually in the grips of acute stress overload. Chronic stress is the most harmful type of stress. If chronic stress is left untreated over a long period of time, it can significantly and often irreversibly damage your physical health and deteriorate your mental health. People with Chronic stress require extended medical and psychological treatment that includes behavioral and stress management. Chronic stress kills through suicide, violence, homicide, heart attack, stroke and, perhaps, even cancer.

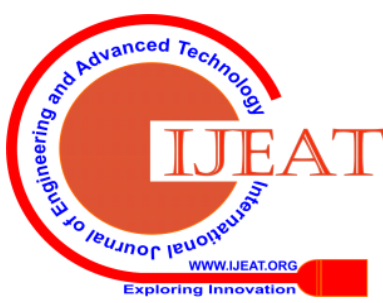




\section{Timely use of Technology to Reduce Perpetuate Stress Impacts}

\section{EFFECTS OF STRESS}

Acute stress can be helpful as it may motivate us to complete our work in given period of time. But chronic stress may lead to serious depression. If this condition is left unnoticed it may have serious effects on body[2].

When any person is in stress, the human body releases stress hormones called adrenaline and cortisol. This makes our heartbeats run at faster rate. Other changes in human are body tighten up and blood pressure rises also there can be trouble in breathing. Chronic stress may lower our immune system, digestive system and even our reproductive system and damage them to great extent. It also cause heart attack or stroke. Stress can also speed up our aging process [2][3]. Stress can cause serious problems on human body such as high blood pressure, heart disease, obesity, diabetes and even when a lady is pregnant it can cause abortion. Stress can alter the immune system which leads to reducing the tolerating power of the human [3]. Stress causes $60 \%$ of the overall illness of our body[5].

There are many more such effects of stress which can damage our healthy life unknowingly. Hence care must be taken before it takes a giant condition.

\section{STRESS RELIEF TECHNIQUES}

There are many stress relief techniques such as yoga, exercise, listening music, take a nap, play with pets

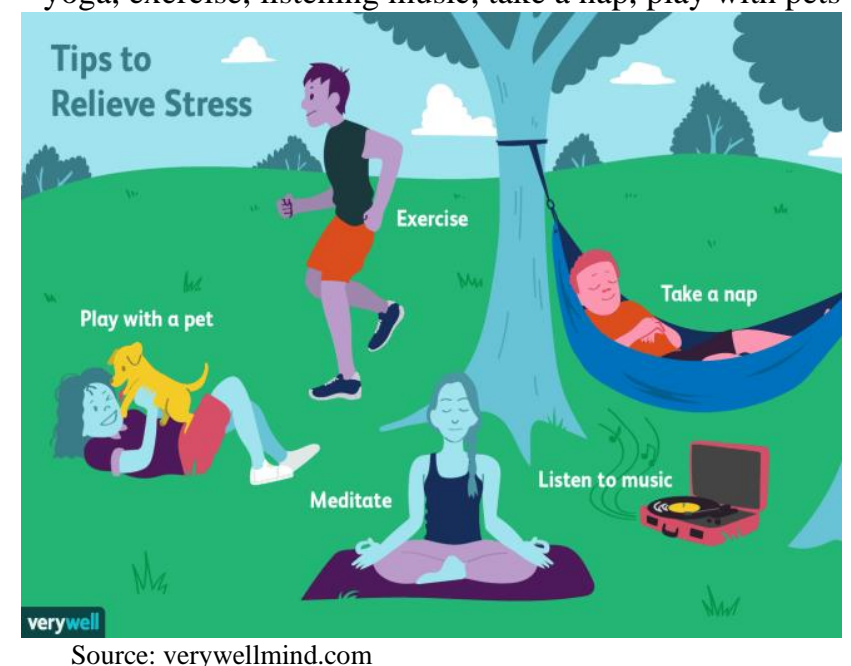

\section{MUSIC IMPACTS ON STRESS}

- Increases happiness: When we listen to our favorite music for at least 10-15 minutes our brain releases dopamine, which is a neurotransmitter which leads to raise the happiness, joy and excitement when listening to music

- Decreases stress and Increases health: Music affects our hormones directly. When we listen to our favorite music it lowers the cortisol level in our body, which can counteract on chronic stress [5].

- Improves sleep: A study showed that over 30\% of the population suffers from insomnia. But listening to classical or relaxing music before going to bed improves the sleep quality significantly .

- Strengthens learning and memory: Researchers say that listening music can help us learn and recall anything very effectively.
Music is a way to bypass rational side of our life and to get in touch with the emotional side of our life. Hence with all these advantages Music is used in this project as a tool for reducing stress

\section{WORK SETUP}

Brainwave recorder is designed using types of amplifier such as instrumentation amplifier, operational amplifier, high conductive electrodes which are dry gel type as they give excellent trace results. Overall gain of 500 is required which is obtained as given below:

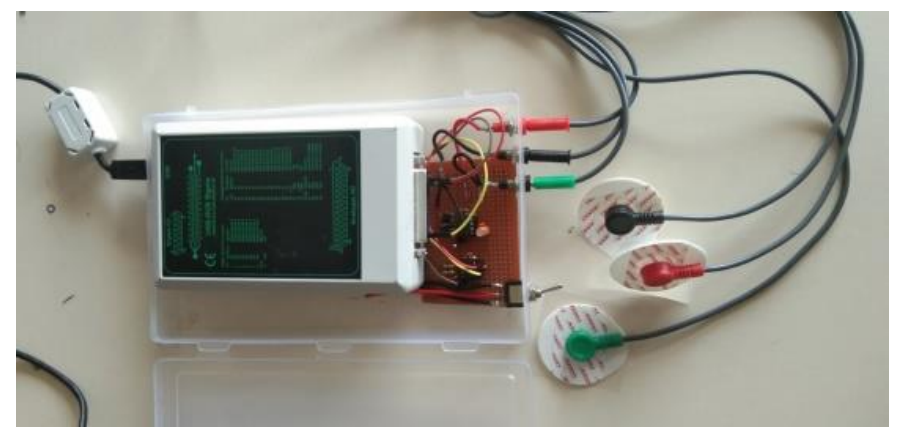

Fig. 2.Experimental Setup

- Instrumentation Amplifier:

AD620 is a low cost high accuracy instrumentation amplifier which requires only 1 external resistor to set gain upto 1 to 10000. The gain can be calculated as

$\mathrm{G}=(49.4 \mathrm{~K}-\mathrm{Rg}) / \mathrm{Rg}$

Where $\mathrm{Rg}$ is the external gain resistor connected between pin 1 and pin 8 of the IC.

Here we want gain as 5 . Hence by substituting the value of $G$ as 5 , we get $\mathrm{Rg}$ as $7.4 \mathrm{Kohm}$.

-Operational Amplifier :

Here for amplification we are using Operational amplifier i.e. Op-amp IC741.This IC comes in 8-pin package whose output pin is 6, inverting input is pin 2 and non-inverting input is pin 3. Pin 7 is Positive supply + Vcc and pin 4 is negative supply -VCC. Pin 1,5 and 8 are for offset null.

We have to build a non inverting amplifier with gain 100 Therefore, $\mathrm{G}=1+\mathrm{R} 1 / \mathrm{R} 2 \quad \ldots .$. the ratio of $\mathrm{R} 1 / \mathrm{R} 2$ must be 99 So practical value of R1 will be $100 \mathrm{Kohm}$ and $\mathrm{R} 2$ will be 1 kohm

$$
\begin{aligned}
G & =1+100 k / 1 k \\
G & =1+100 \\
G & \sim 101
\end{aligned}
$$

\section{WORK DONE}

Brainwaves of 42 students were recorded in three phases.

- 30 minutes before exam

- Immediately after exam

- After giving music 
Students were from Dr. D. Y. Patil Institute of Technology Pimpri Pune. These students were selected such that they were about to attend there exam. Hence before going for exam each student's readings were recorded, then after they finish their exam brainwaves were recorded for each and finally a music was allowed to listen for 2-3 min for each student and again brainwaves were recorded. Hence we got three set of readings i.e. before exam, after exam and after listening music. Finally a graph was plot which shows that students who were stressed before and after going to exam, their stress was released after listening their favorite music. Table I shows sample of the recorded brainwave and figure 5 shows the statistical representation of recorded brainwaves.

A. Steps followed during recording of Brainwaves:

- If the recorded wave is stressed, then music was played and ones again brainwaves were recorded

- The music played was of the students choice

- This music played for 4 minutes.

- Later to which brainwaves were recorded.

Table- I: Sample of recorded Brainwave

\begin{tabular}{|c|c|c|c|c|c|}
\hline Sr. No. & Before Exam & After Exam & After Listening Music & $\begin{array}{c}\text { Frequency } \\
\text { difference }\end{array}$ & $\begin{array}{c}\text { Time for music in } \\
\text { min }\end{array}$ \\
\hline 1 & 16.27 & 11.55 & 11.5 & 0.05 & 2.3 \\
\hline 2 & 14.12 & 11.16 & 11.29 & -0.13 & 3 \\
\hline 3 & 14.14 & 9.76 & 9.85 & -0.09 & 2.4 \\
\hline 4 & 11.5 & 11.61 & 11.29 & 0.32 & 2.1 \\
\hline 5 & 11.29 & 11.29 & 11.08 & 0.21 & 2.9 \\
\hline 6 & 14.85 & 9.38 & 11.8 & -2.42 & 2.7 \\
\hline 7 & 14.58 & 16.27 & 11.88 & 4.39 & 2.8 \\
\hline 8 & 13.33 & 14.11 & 9.11 & 5 & 2.4 \\
\hline 9 & 11.29 & 11.16 & 10.32 & 0.84 & 2.6 \\
\hline 10 & 11.08 & 11.31 & 9.36 & 1.95 & 2.5 \\
\hline 11 & 13.3 & 11.25 & 10.76 & 0.49 & 3.1 \\
\hline
\end{tabular}

\section{BRAINWAVE ANALYSIS}

From the recorded brainwave frequencies we can calculate the amount of brainwaves dropped after listening music.

Therefore,

$\%$ decrease in stress $=\{($ stress freq - No stress $) /$ stress freq $\}$ * 100

$=28.67 \%$

Hence it is found that approx. $29 \%$ of decrease in stress is obtained.

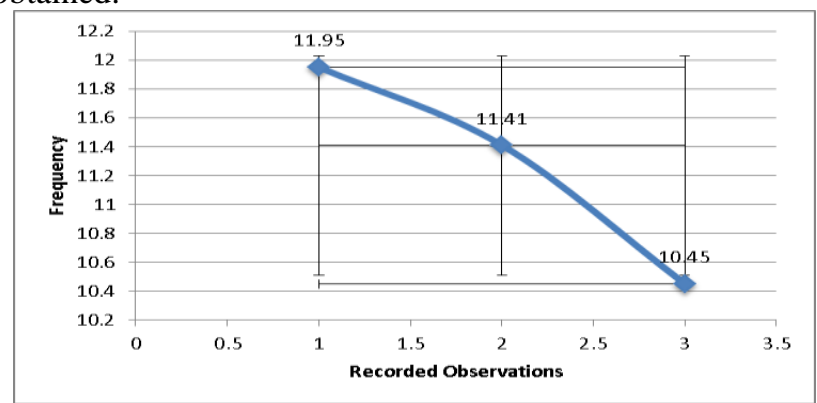

Fig. 3.Statistical Analysis of Brainwave
The above figure shows the details of recorded brainwaves in various stages. It indicates that music effects does impact the stress. Figure 3 shows the decrease in stress after giving the music.

\section{RESULT AND DISCUSSION}

We have used Neural Networks for feature extraction. Here we have processed on normalized magnitude data for feature extraction. Fig 6 shows Pattern recognition of Neural Network.

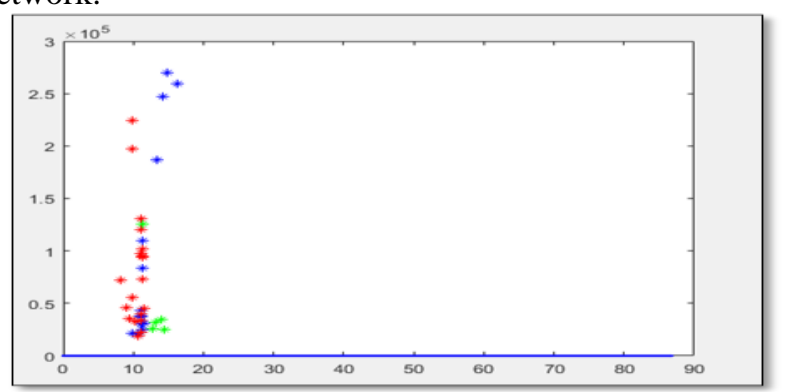

Fig. 4.Scattered Plot

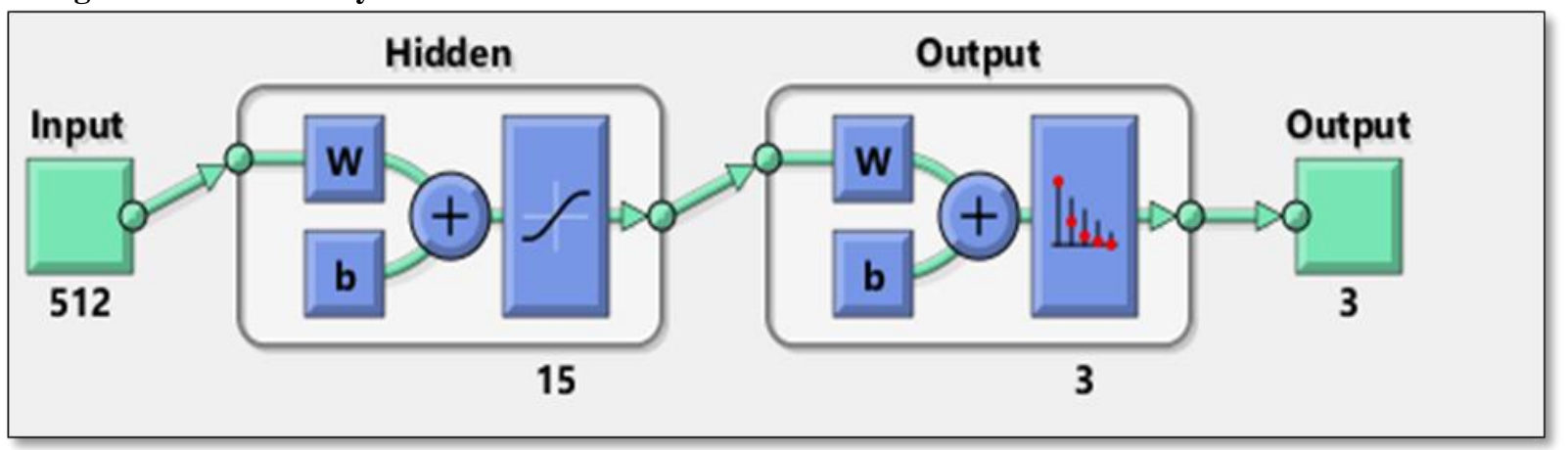

Fig. 5.Pattern Recognition using Neural Network 
Timely use of Technology to Reduce Perpetuate Stress Impacts

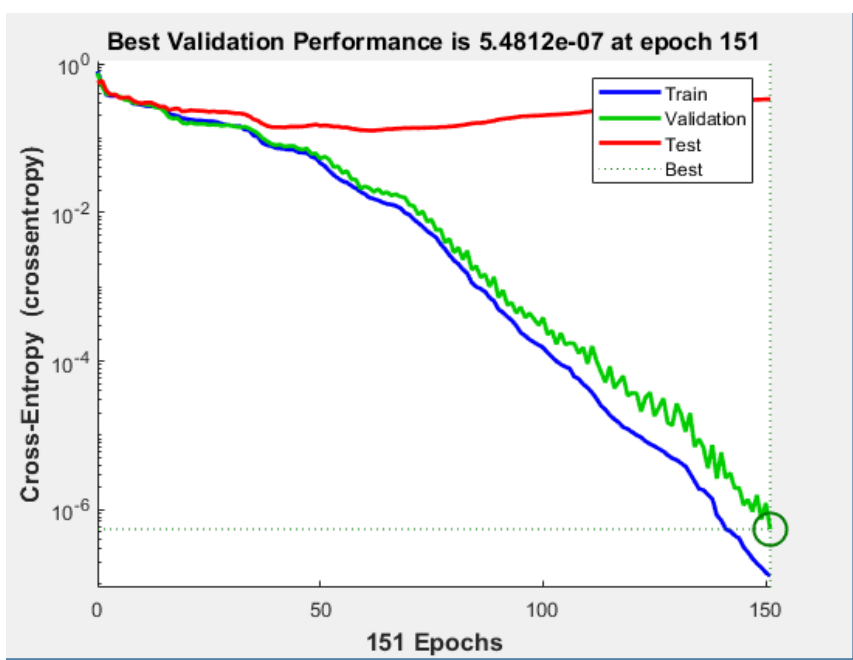

Fig. 6.Neural Network Training Performence

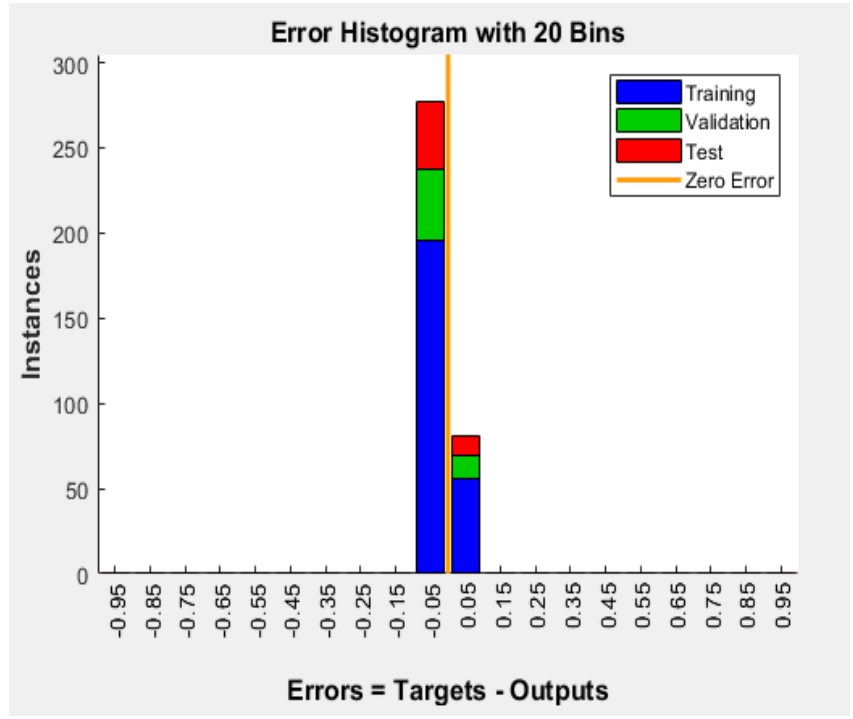

Fig. 7.Error Histogtam

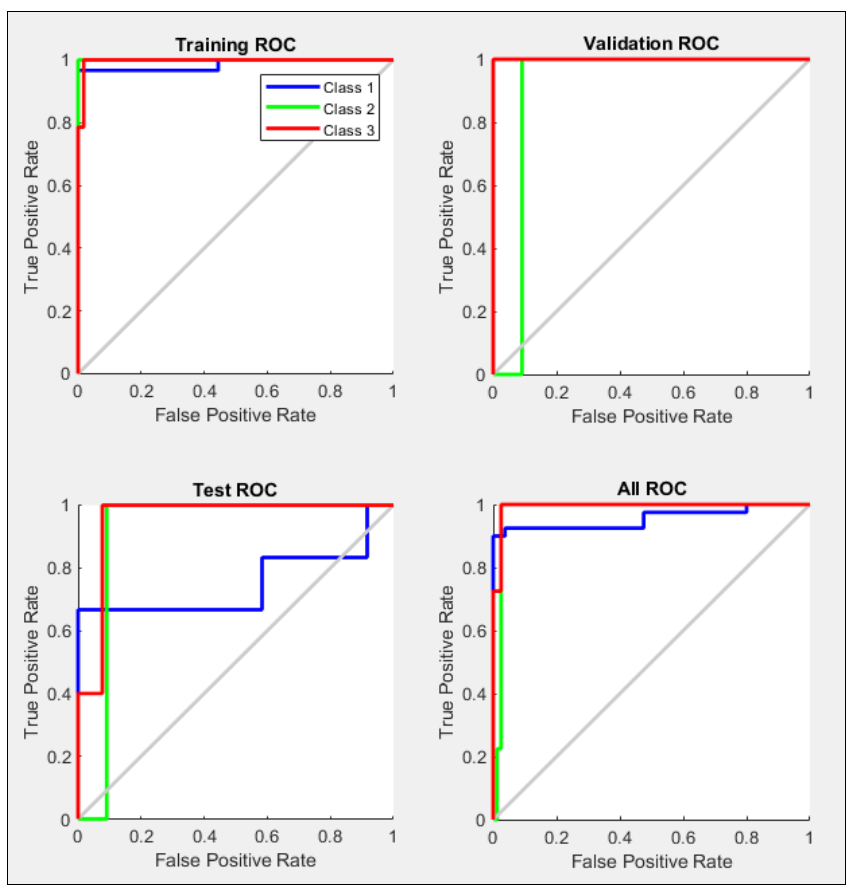

Fig. 8. Receiver Operating Characteristic

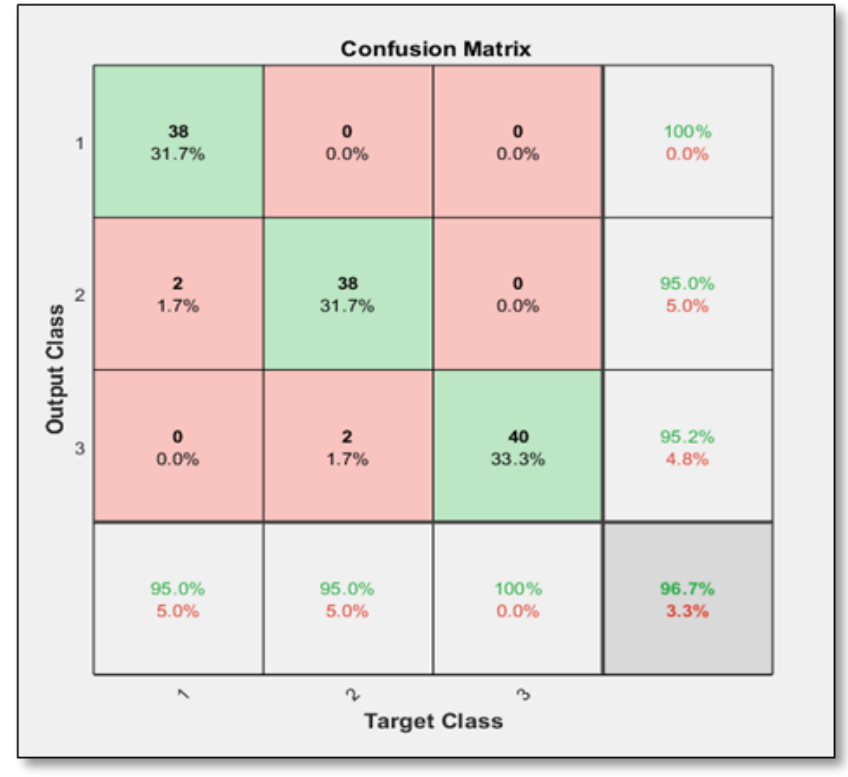

Fig. 9.Confusion Matrics

\section{CONCLUSION}

A simple, easy, portable and economical system is developed to record brainwave. This does not need any technical efficient person to use it but needs to be used under expert supervision. This system will prevent leading to stress disorder like post-traumatic stress disorders, acute stress, episodic stress and chronic stress. Hence use of this system can timely avoid use of abnormalities.

\section{ACKNOWLEDGMENT}

This project was developed in association with Dr. D. Y. Patil Medical Hospital and research center Pimpri Pune. Department of Neurology and Department of psychiatric have supported in experimentation and validation of data, results and system. Next we would like to thank all 42 students for their kind support in completing this experiment. And last but not the least we would like to thank all who supported us knowingly or unknowingly to complete this experiment.

\section{REFERENCES}

1. Shawna Freshwater, Ph.D. - Clinical Psychologist NeuroPsychologist \& Holistic Healer, January 17, 2018, 3 Types of Stress and Health Hazards, Retrieved from https://spacioustherapy.com/3-types-stress-health-hazards/

2. Association, A. P. (2019, nov 15). Global Organization for stress. Retrieved from http://www.gostress.com/stress-facts/.

3. Chiara Samele, H. L.-M. (2018). Stress : Are we coping? mentalhealth.org.uk.

4. Mrs. Mamta S. Kalas, D. B. (2016). Stress Detection and Reduction using EEG Signals. International Conference on Electrical, Electronics, and Optimization Techniques (ICEEOT) - 2016 (p. 5) 978-1-4673-9939-5/16/\$31.00 (C2016 IEE.

5. Saras, H. (2016). Shocking Statistics of Workplace Stress You Never Knew. Retrieved from https://www.harishsaras.com/stress-management/shocking-statistics-o f-workplace-stress/.

6. Deflin, K. (2016, Feb 17). Live for live Music. Retrieved from 10 Positive Benefits Of Listening To Music, According to Science: https://liveforlivemusic.com/features/10-positive-benefits-of-listening -to-music-according-to-science/

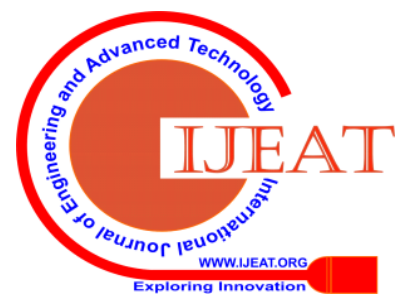


7. Y. Liu, O. Sourina and M. K. Nguyen, "Real-Time EEG-Based Human Emotion Recognition and Visualization," Cyberworlds (CW), 2010 International Conference on, Singapore, 2010, pp. 262-269.

8. P. Hoole et al., "Autism, EEG and brain electromagnetics research," Biomedical Engineering and Sciences (IECBES), 2012 IEEE EMBS Conference on, Langkawi, 2012, pp. 541-543

9. Andrew Campbell et al. "NeuroPhone: brain-mobile phone interface using a wireless EEG headset", Proceedings of the second ACM SIGCOMM workshop on Networking, systems, and applications on mobile handhelds, ACM, pp.3-8, 2010.

10.Christos Papadelis et al. "Using brain waves to control computers and machines", Advanced Human-Computer Interaction, vol. 2013. New York: Hindawi Publishing Corporation, pp.1-2, 2013.

11.TM Vaughan et al. "Brain-computer interface technology: a review of the Second International Meeting", IEEE transactions on neural systems and rehabilitation engineering: a publication of the IEEE Engineering in Medicine and Biology Society 11, No. 2, pp. 94-109. 2003

12.Bi, Luzheng, Xin-An Fan, Yili Liu, "EEG-based brain-controlled mobile robots: a survey", IEEE Transactions on Human-Machine Systems, Vol.43, No. 2, pp. 161-176, 2013.

13.JR Millán et al. "Combining brain-computer interfaces and assistive technologies: state-of-the-art and challenges", Frontiers in neuroscience 4, p. 161, 2010.

14.AnkitaTiwari and RajinderTiwari "Design of a Brain Computer Interface for Stress Removal Using Yoga a Smartphone Application"

15. "Study and application of brainwaves" G. AmbicaB.Sujata 2015

16."Alpha and Beta Brainwave Characteristics to Binaural Beat treatment" N.S.MohdPuziR.Jailani Mohammad Zaini 2013

17.F. Lebepe, G. Niezen, G.P. Hancke and T.D. Ramotsoela 2016 "Smart and wearable band for stress detection"

18.Muhammad Zubair, Changwoo Yoon 2016 "Wearable Stress Monitoring System Using Multiple Sensors "

19.VivekanandJha*, NupurPrakash, SwetaSagar Wearable anger-monitoring system.

20.Mario Salai, IstvanVassanyi and IstvanKosa "Stress detection using low cost Heart rate sensors"

21.Garcia Cortes, J. Marti, I. Sayago, J.P.Santos, "Detection of stress through sweat analysis with an electrode nose" Feb 2009 Spanish conferenceon Electronic devices.

22.www.google.com/amp/s/amp.livescience.com/49452-trackers-measure-s tress-heart-rate-variability.html

23.Andrew Campbell et al. in his paper NeuroPhone: brain-mobile phone interface using a wireless EEG headset

\section{AUTHORS PROFILE}

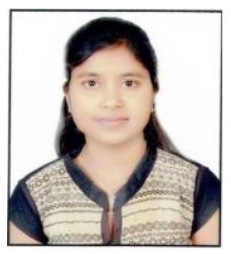

Ms Shubhangi Gond is a PG student from Dr. D. Y. Patil Institute of Technology Pimpri Pune in Department of Electronics \& Telecommunication Engineering.Currently she is working as a Lab Assistant in Dr. D. Y. Patil Institute of Technology Pimpri Pune. She has been doing research in Biomedical Engineering since 2 years. She has completed B.E. from Jawaharlal Nehru Engineering College Aurangabad.

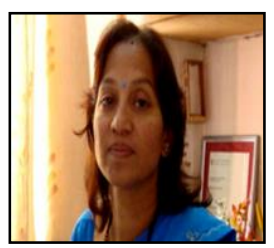

Dr. Bhavna Ambudkar is currently working as Professor in Department of Electronics \& Telecommunication Engineering and Dean Industry Institute \& Alumni interaction at Dr. D. Y. Patil Institute of Technology, Pimpri, Pune.She is Ph. D in Engineering and currently doing research in the field of Education Technology. She is awarded Cambridge Certification for Teachers and Trainers (CICTT) and also has completed Dale Carniegie certification.Current designation: ProfessorDepartment of Electronics \& Telecommunication Engineering. Dean- Alumni Network \& Industry Institute Relations. Coordinator- Innovation \& Entrepreneurship Development Cell.Qualification: Ph. D (Engineering), M. Tech (Electronics \& Telecommunication Engineering) .Industry Experience: 2 years, Teaching Experience: 21 years. Professional Body Memberships: Member of IETE (Institution of Electronics \& Telecommunication Engineers)Member of IACSIT (International Association of Computer Science and Information Technology).Member of IAENG (International Association of Engineers)

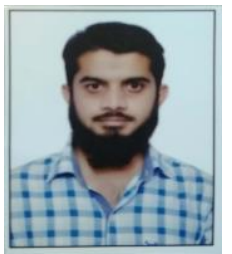

Mr. Afzal Ali Syed is B.E. student from Dr. D. Y. Patil Institute of Technology Pimpri Pune in Department of Electronics \& Telecommunication Engineering. He has been doing research in Biomedical Engineering since 1 years. He has completed Masters Data Science and Machine Learning Fundamentals Course.

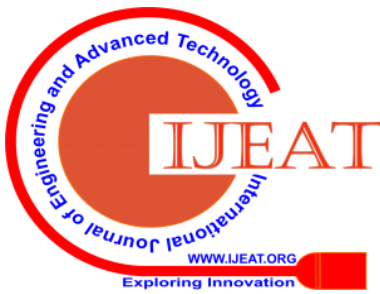

